\title{
Ultrasound measurement of rectus femoris cross- sectional area and the relationship with quadriceps strength in COPD
}

\author{
J M Seymour, ${ }^{1}$ K Ward, ${ }^{1}$ P S Sidhu, ${ }^{2}$ Z Puthucheary, ${ }^{2}$ J Steier, ${ }^{1}$ C J Jolley, ${ }^{1}$ G Rafferty, \\ M I Polkey, ${ }^{3}$ J Moxham'
}

\begin{abstract}
- Additional tables and figures are published online only at http://thorax.bmj.com/content/ vol64/issue5

${ }^{1}$ King's College London Schoo of Medicine, London, UK:

${ }^{2}$ King's College Hospital, London, UK; ${ }^{3}$ Royal Brompton Hospital, London, UK
\end{abstract}

Correspondence to: Dr J Seymour, Department of Respiratory Medicine, King's College Hospital, London SE5 9RJ, UK; john.seymour@kcl.ac.uk

Received 2 July 2008 Accepted 31 December 2008 Published Online First 19 January 2009

\section{ABSTRACT}

Background: Quadriceps weakness and loss of muscle mass predict mortality in chronic obstructive pulmonary disease (COPD). It was hypothesised that a reduced quadriceps cross-sectional area could be detected by ultrasound in patients with COPD compared with healthy subjects, and that measurements relate to strength and fat-free mass (FFM).

Methods: Rectus femoris muscle cross-sectional area $\left(\mathrm{RF}_{\mathrm{CSA}}\right)$ was measured by ultrasound and whole-body FFM estimated using electrical bioimpedance. Quadriceps strength was measured by maximum voluntary contraction and twitch tension (TwO) following magnetic femoral nerve stimulation.

Results: 26 healthy volunteers of mean (SD) age 63 (9) years and 30 patients with COPD of mean (SD) age 67 (9) years and percentage predicted forced expiratory volume in $1 \mathrm{~s}\left(\mathrm{FEV}_{1}\right) 48.0(20.8) \%$ with a similar FFM (46.9 (9.3) $\mathrm{kg}$ vs 46.1 (7.3) kg, $p=0.193$ ) participated in the study. Mean $\mathrm{RF}_{\mathrm{CSA}}$ was reduced in patients with COPD by $25 \%$ of the mean value in healthy subjects $\left(-115 \mathrm{~mm}^{2} ; 95 \% \mathrm{Cl}-177\right.$ to $\left.-54, \mathrm{p}=0.001\right)$ and was related to MRC dyspnoea scale score, independent of FFM or sex. Maximum voluntary contraction strength was linearly related to $\mathrm{RF}_{\mathrm{CSA}}$ in patients with COPD $(r=0.78, p<0.001)$. TwQ force per unit of $R_{C S A}$ was similar in both healthy individuals and those with COPD (mean (SD) 17 (4) g/mm² vs 18 (3) $\mathrm{g} / \mathrm{mm}^{2}, \mathrm{p}=0.657$ ). Voluntary contraction strength per unit of $\mathrm{RF}_{\mathrm{CSA}}$ was dependent on central quadriceps activation and peripheral oxygen saturation in COPD.

Conclusion: Ultrasound measurement of $\mathrm{RF}_{\mathrm{CSA}}$ is an effort-independent and radiation-free method of measuring quadriceps muscle cross-sectional area in patients with COPD that relates to strength.

Even in non-cachectic patients with chronic obstructive pulmonary disease (COPD), quadriceps strength is typically reduced by up to $30 \%$ compared with healthy elderly subjects. ${ }^{1}$ Quadriceps strength has been shown independently to predict increased healthcare utilisation and mortality in COPD. ${ }^{2}$ In our cohort of patients with moderate to severe COPD, quadriceps strength together with age provided more powerful prognostic information than whole body fat-free mass (FFM) or forced expiratory volume in $1 \mathrm{~s}$ $\left(\mathrm{FEV} \mathrm{V}_{1}\right)^{3} \mathrm{~A}$ related measure, mid-thigh cross-sectional area measured by computed tomography (CT), has also been shown to predict mortality. ${ }^{4}$

Quadriceps strength may be assessed by maximum voluntary contraction force, but maximum effort cannot be guaranteed and formal testing equipment is cumbersome. ${ }^{56}$ Effort-independent methods of assessing strength such as femoral nerve stimulation are expensive, not widely available and require specific expertise. ${ }^{7}$ Bedside tests are attractive for their simplicity and accessibility but measurement of thigh circumference, for example, may not accurately reflect the muscle compartment. Ionising radiation exposure makes serial measurements with $\mathrm{CT}^{4}$ or dual energy $x$ ray absorptiometry scanning ${ }^{8}$ undesirable in large populations. MRI avoids this concern, but accessibility and long scanning times remain clinically relevant constraints.

Ultrasound can be used to assess limb muscle size and has been compared with CT and MRI in other research scenarios. ${ }^{10}{ }^{11}$ While CT and MRI of the quadriceps are described in COPD ${ }^{12}{ }^{13}$ ultrasound is not widely used. Ultrasound equipment is available in most hospitals and, in principle, trained non-specialists could perform scans rapidly at the bedside. We hypothesised that ultrasound could detect reduced quadriceps muscle size in patients with COPD compared with healthy subjects. We wished to explore how muscle size measured in this manner correlated with quadriceps strength and FFM.

\section{METHODS}

\section{Study design and participants}

Community dwelling healthy volunteers and patients with stable $\mathrm{COPD}^{14}$ aged $40-90$ years were invited to participate. Healthy subjects had an MRC dyspnoea score of $1,{ }^{15}$ no spirometric evidence of airflow obstruction and reported no organ dysfunction or co-morbidity affecting the legs. Subjects with COPD were recruited from a respiratory outpatient clinic and had attended a pulmonary rehabilitation course in the preceding year. All were exacerbation-free for at least 4 weeks.

Participants underwent spirometry, FFM measurement and assessment of the right quadriceps. In addition they consented to undergo supplementary studies described below; participation in these additional tests was voluntary, unselected and intended to provide technical and supporting information only.

\section{Measurements}

Spirometry was performed according to international recommendations. ${ }^{14}{ }^{16} \mathrm{FFM}$ was determined 


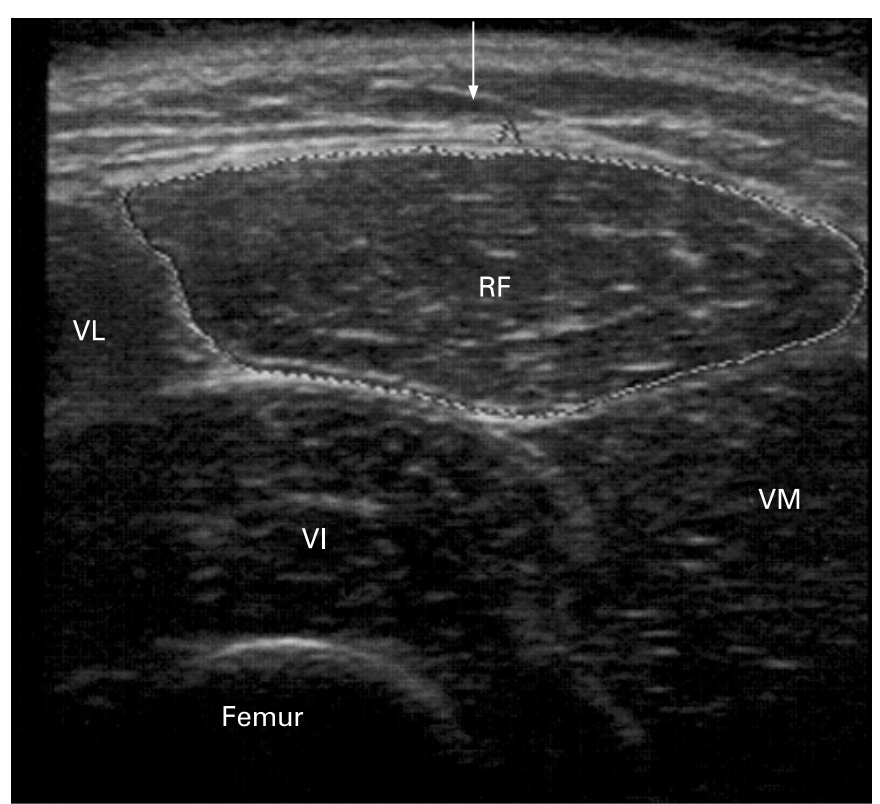

Figure 1 Ultrasound of the quadriceps. Sample ultrasonogram of the right quadriceps in a healthy woman aged 59 years. The arrow indicates the direction of the scan ( $5 \mathrm{~cm}$ scanning depth displayed). RF, rectus femoris; VL, vastus lateralis; VM, vastus medialis; VI, vastus intermedius.

by electrical bioimpedance (Bodystat 1500; Bodystat, Isle of Man, UK). A disease-specific equation was applied in patients with COPD. ${ }^{9}$ Quadriceps strength was assessed by isometric maximum voluntary contraction (OMVC) and twitch tension (TwQ) following supramaximal magnetic femoral nerve stimulation. OMVC was measured supine on custom-made apparatus based on that used by Edwards et al. ${ }^{5}$ Participants performed isometric contractions with the knee joint at $90^{\circ}$ until consistent traces within $5 \%$ of the maximum were obtained. QMVC was taken as the highest mean tension maintained over $1 \mathrm{~s}$. Twitch tension was measured using the method of Polkey et al. ${ }^{7}$ Unpotentiated twitches were obtained following $20 \mathrm{~min}$ quadriceps rest using a $70 \mathrm{~mm}$ figure-of-eight coil (Magstim, Whitland, UK). Non-supramaximal responses were discarded. A measure of voluntary quadriceps activation (twitch interpolation) was derived by superimposing twitches during the QMVC. ${ }^{6}$

\section{Quadriceps ultrasound}

Cross-sectional area of the rectus femoris $\left(\mathrm{RF}_{\mathrm{CSA}}\right)$ was measured by B-mode ultrasonography using an $8 \mathrm{MHz} 5.6 \mathrm{~cm}$ linear transducer array (PLM805, Toshiba Medical Systems, Crawley, UK), similar to the method of de Bruin et al. ${ }^{17}$ The transducer was placed perpendicular to the long axis of the thigh on its superior aspect, three-fifths of the distance from the anterior superior iliac spine to the superior patellar border. This was the highest point in the thigh that the entire rectus femoris crosssection could be visualised in a single field in all subjects; other muscles of the quadriceps group could not be encompassed in this manner. Imaging was conducted supine with the rested leg supported in passive extension. Excess contact gel was applied to minimise underlying soft tissue distortion. Oblique imaging was minimised by the operator (JS) using visual feedback to obtain the smallest cross-sectional image. Scanning depth was set to where the femur could be discerned for orientation. Gentle contraction-relaxation manoeuvres were employed to delineate muscle septa prior to image acquisition. $R_{\text {CSA }}$ was calculated by a planimetric technique (Nemio, Toshiba Medical Systems) after the inner echogenic line of the rectus femoris was outlined by a movable cursor on a frozen image (fig 1 ). $\mathrm{RF}_{\mathrm{CSA}}$ was taken as an average of three consecutive measurements within $10 \%$.

\section{Supporting studies}

Although related information is described elsewhere, ${ }^{10}{ }^{11}$ the findings of de Bruin et al did not report specific information regarding the relationship of the $\mathrm{RF}_{\mathrm{CSA}}$ and other scanning modalities such as CT. A subset of volunteers underwent CT scanning of the quadriceps for comparison with the ultrasound scans taken in this study. CT scans were performed using a Siemens SOMATOM Sensation 64-slice scanner, similar to the method of Bernard et al..$^{12}$ Scans were taken at the mid-point of a line between the pubic symphysis and tibial plateau. Mid-thigh, quadriceps and rectus femoris muscle cross-sectional areas were calculated using Siemens SIENET software (MagicView VE 40) after manual outline with a movable cursor. Inter-occasion repeatability of right leg $\mathrm{RF}_{\mathrm{CSA}}$ measurement was assessed in a subset of healthy and COPD volunteers after an interval of 2 4 weeks, during which subjects continued their normal level of daily activity. Images and force traces were archived and analysed following completion of data collection. Inter-observer agreement was assessed between two observers (JS and PS), each blind to the other's scans.

\section{Statistical analysis}

Based on previous data, 25 patients in each group were required for an $80 \%$ chance of detecting a $20 \%$ reduction in the mean TwO of patients with COPD compared with healthy subjects at the $5 \%$ significance level. ${ }^{1}$ Similar to the source of this calculation, all volunteers were analysed prospectively; no direct case matching was performed. Differences were not sought between healthy subjects and those with COPD in the technical and supporting studies. Mean differences between healthy and COPD groups were analysed with unpaired $t$ tests or MannWitney U tests; normality was assessed by the D'Agostino and Pearson omnibus method. Correlations were described using Pearson coefficients (or Spearman rho for non-normally distributed or categorical data) to two decimal places with accompanying two-tailed $\mathrm{p}$ values. Multiple linear regression analysed the relationship between $\mathrm{RF}_{\mathrm{CSA}}$ and FFM (the continuous variable) with sex and disease group as categorical

Table 1 Baseline demographic characteristics

\begin{tabular}{lllc}
\hline & $\begin{array}{l}\text { Healthy } \\
(\mathbf{n}=\mathbf{2 6})\end{array}$ & $\begin{array}{l}\text { COPD } \\
(\mathbf{n}=\mathbf{3 0})\end{array}$ & p Value \\
\hline Age (years) & $63(9)$ & $68(9)$ & 0.093 \\
Sex (M:F) & $11: 15$ & $16: 14$ & $0.579^{*}$ \\
Weight $(\mathrm{kg})$ & $70.4(11.8)$ & $72.6(15.8)$ & 0.562 \\
$\mathrm{BMI}\left(\mathrm{kg} / \mathrm{m}^{2}\right)$ & $25.0(3.5)$ & $26.0(4.5)$ & 0.348 \\
FFM $(\mathrm{kg})$ & $46.9(9.3)$ & $46.1(7.3)$ & 0.730 \\
FFMI $\left(\mathrm{kg} / \mathrm{m}^{2}\right)$ & $16.5(1.8)$ & $16.7(2.0)$ & 0.616 \\
$\mathrm{Smoking}^{2}($ pack-years) & $14(14)$ & $45(30-50)$ & $<0.001 \dagger$ \\
$\mathrm{FEV}_{1}(\mathrm{l})$ & $2.85(0.67)$ & $1.09(0.78-1.51)$ & $<0.001 \dagger$ \\
$\mathrm{FEV}_{1}(\%$ predicted) & $109(14)$ & $48(28-69)$ & $<0.001 \dagger$ \\
$\mathrm{Sa0}_{2}(\%)$ & $98(1)$ & $95(2)$ & $<0.001$ \\
\hline
\end{tabular}

Data are mean (SD) or median (interquartile range) where appropriate.

$\mathrm{p}$ Values derived from unpaired $t$ tests, $\chi^{2}$ test with Yates' continuity correction (indicated by ${ }^{*}$ ) or the Mann-Witney test (indicated by ${ }^{\dagger}$ ).

$\mathrm{BMI}$, body mass index; FFM, fat-free mass; FFMI, fat-free mass index; $\mathrm{FEV}_{1}$, forced expiratory volume in $1 \mathrm{~s}$; $\mathrm{SaO}_{2}$, resting peripheral oxygen saturation measured by pulse oximetry. 
variables. The MRC dyspnoea score was also included in an analysis of patients with COPD. Bland-Altman analysis ${ }^{18}$ described agreement between observers and interval RFCSA scans. Analysis and figure construction used SPSS Version 16.0 (SPSS Inc, Chicago, Illinois, USA) or GraphPad Prism Version 5.0 (GraphPad Software, San Diego, California, USA).

\section{RESULTS}

\section{Participants}

Thirty patients with stable COPD and 26 healthy volunteers participated in the study. The median MRC dyspnoea score was 3 (interquartile range 2.75-4.00) in patients with COPD. 25 were prescribed inhaled corticosteroid and 28 took at least one long-acting bronchodilator; none took oral corticosteroids. Baseline characteristics are shown in table 1.

\section{Quadriceps strength and $\mathbf{R F}_{\mathbf{c S A}}$}

Supramaximal TwQ responses were unobtainable in one healthy subject and four with COPD. OMVC and TwO were correlated with a Pearson coefficient of $0.81(p<0.001)$. The TwO/OMVC ratio was similar in healthy and COPD groups (median (IOR) $0.22(0.20-0.28)$ and $0.25(0.19-0.30), \mathrm{p}=0.359)$ as was twitch interpolation $(0.90(0.86-0.96)$ and $0.92(0.82-$ $0.95, p=0.955)$. Individual $R_{C S A}$ results are shown in fig 2 . Mean group differences for quadriceps strength and $\mathrm{RF}_{\mathrm{CSA}}$ are shown in table 2.

\section{Relationship between quadriceps strength and $\mathbf{R F}_{\text {cSA }}$}

Quadriceps strength shared a linear relationship with $\mathrm{RF}_{\mathrm{CSA}}$ in both healthy subjects (QMVC, $\mathrm{r}=0.80$; TwQ, $\mathrm{r}=0.72$; $\mathrm{p}<0.001$ ) and patients with COPD (OMVC, $\mathrm{r}=0.78$; TwQ, $\mathrm{r}=0.69, \mathrm{p}<0.001)$. The relationship was similar between groups (table 2, fig 3). Greater OMVC strength per unit of $\mathrm{RF}_{\mathrm{CSA}}$ correlated with higher twitch interpolation values in both groups. Greater $\mathrm{OMVC} / \mathrm{RF}_{\mathrm{CSA}}$ was noted among healthy subjects with fewer recorded smoking pack years $(r=0.50$, $\mathrm{p}=0.009)$ and in patients with COPD with a higher resting $\mathrm{SaO}_{2}(\mathrm{r}=0.41, \mathrm{p}=0.025)$; neither correlated with $\mathrm{TwO} / \mathrm{RF}_{\mathrm{CSA}}$ or absolute QMVC.

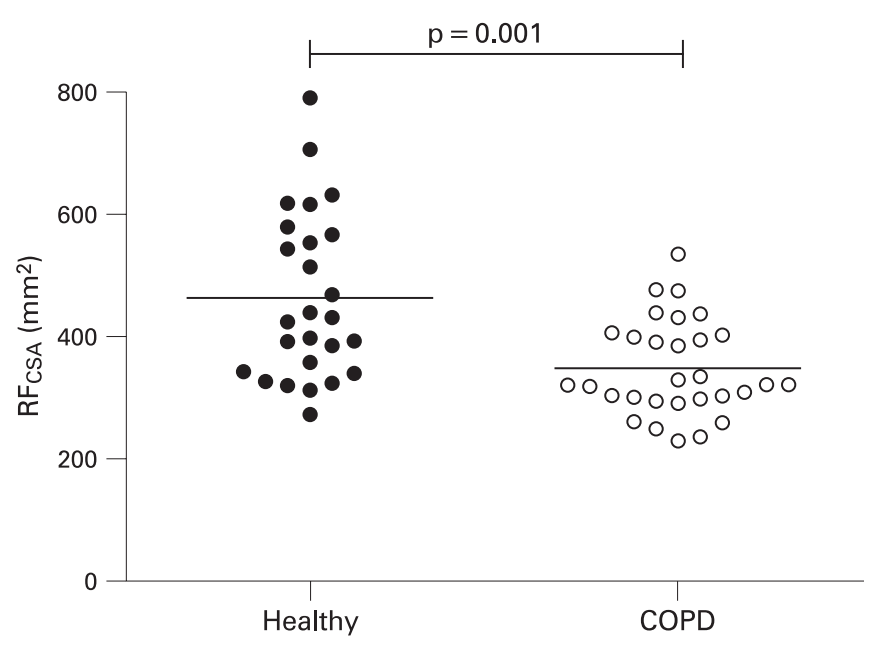

Figure 2 Rectus femoris cross-sectional area $\left(\mathrm{RF}_{\mathrm{CSA}}\right.$, in $\left.\mathrm{mm}^{2}\right)$ in healthy subjects (solid circles) and subjects with chronic obstructive pulmonary disease (open circles). Horizontal lines indicate mean values.

\section{Relationship between rectus femoris size and FFM}

OMVC, TwQ, RF CSA and FFM were significantly larger in men, irrespective of disease status (mean (SD) $\mathrm{RF}_{\mathrm{CSA}}$ in men 460 (133) $\mathrm{mm}^{2}$ vs 347 (83) $\mathrm{mm}^{2}$ in women, $\mathrm{p}<0.001$ ). FFM, as opposed to weight, BMI or FFMI, displayed the closest correlations with $\mathrm{RF}_{\mathrm{CSA}}$ and quadriceps strength. Age did not determine $\mathrm{RF}_{\mathrm{CSA}}$ or quadriceps strength in those studied, nor did $\mathrm{FEV}_{1}$ or $\mathrm{SaO}_{2}$ among subjects with COPD.

$\mathrm{RF}_{\mathrm{CSA}}$ correlated with FFM in both healthy subjects $(r=0.66$, $p<0.001)$ and those with COPD $(r=0.43, p=0.019)$; regression slopes were not significantly different $(p=0.263)$. The relation in healthy subjects remained significant $(p=0.024)$ when adjusted for greater $\mathrm{RF}_{\mathrm{CSA}}$ in men (table 3 , model I), but was no longer significant in patients with COPD $(p=0.24$, model II). Allowing for sex and the dependence of RFCSA on FFM, $\mathrm{RF}_{\mathrm{CSA}}$ was smaller in patients with COPD than in healthy subjects $\left(-121 \mathrm{~mm}^{2}\right.$ (95\% CI -166 to -76$\left.), \mathrm{p}<0.001\right)$. Analysis of MRC dyspnoea score as an independent variable showed that it explained more of the variation in $\mathrm{RF}_{\mathrm{CSA}}$ in patients with COPD than FFM and sex (models II and III) and, in a model with all three variables, remained statistically significantly associated with $\mathrm{RF}_{\mathrm{CSA}}$ while FFM and sex no longer showed a relation (model IV). This was not found to be the case with $\mathrm{FEV}_{1}$ or $\mathrm{SaO}_{2}$ if substituted for MRC score.

\section{Supporting studies}

Eighteen participants agreed to an additional CT scan of the quadriceps. RF $\mathrm{CSA}$ measured using ultrasound significantly correlated with that measured by CT (intraclass coefficient $r=0.88)$. No significant bias was associated with either modality. The relationship of $\mathrm{RF}_{\mathrm{CSA}}$ to the whole quadriceps cross-sectional area $\left(Q_{\text {CSA }}\right)$ is shown in fig 4 . The relationship between strength in these 18 subjects and the different measured cross-sectional variables on CT are described further in the online supplement.

Nineteen volunteers underwent repeat measurement of $\mathrm{RF}_{\mathrm{CSA}}$ on two occasions. The mean (SD) bias and $95 \%$ limits of agreement were 12 (43) $\mathrm{mm}^{2}$ and -72 to $+96 \mathrm{~mm}^{2}$. The coefficient of repeatability was $85 \mathrm{~mm}^{2}$ and index of reliability 0.97 . The corresponding values for interobserver $\mathrm{RF}_{\mathrm{CSA}}$ measurement $(\mathrm{n}=10)$ were $2(32) \mathrm{mm}^{2},-61$ to $+65 \mathrm{~mm}^{2}, 64 \mathrm{~mm}^{2}$ and 0.99 .

\section{DISCUSSION}

This study shows that ultrasound can generate a simple measure of quadriceps muscle cross-sectional area that is related to strength in both healthy persons and patients with COPD. The $\mathrm{RF}_{\mathrm{CSA}}$ was reduced in COPD by $25 \%$ of the mean value observed in a healthy population with a similar FFMI.

\section{Experimental critique}

Inter-observer and inter-occasion agreements for ultrasound $\mathrm{RF}_{\mathrm{CSA}}$ measurement were comparable to other reported clinical ultrasound measures (eg, carotid artery intimal thickness ${ }^{19}$ ). Measurement differences are probably operator-related, such as oblique imaging of the $\mathrm{RF}_{\mathrm{CSA}}$ or placement of an inaccurate cursor outline for area calculation. Previous studies suggest that differences between serial CT or MRI cross-sectional area measurements ${ }^{20}$ are smaller than those observed for ultrasound. Certainly these modalities can use bony landmarks for position more accurately than surface anatomy. Ascertaining the scanning point between visits seems important as evidenced by the narrower inter-observer limits of agreement (when 
Table $2 \mathrm{RF}_{\mathrm{CSA}}$ and quadriceps strength

\begin{tabular}{|c|c|c|c|c|c|}
\hline & $\begin{array}{l}\text { Healthy } \\
(n=26)\end{array}$ & $\begin{array}{l}\text { COPD } \\
(n=30)\end{array}$ & $\begin{array}{l}\text { Mean difference } \\
(95 \% \mathrm{CI})\end{array}$ & $\begin{array}{l}\text { Mean difference } \\
\text { (\% of mean } \\
\text { value in healthy } \\
\text { subjects) }\end{array}$ & p Value \\
\hline $\mathrm{RF}_{\mathrm{CSA}}\left(\mathrm{mm}^{2}\right)$ & 463 (137) & $348(78)$ & $-115(-177$ to -54$)$ & -25 & 0.001 \\
\hline OMVC $(\mathrm{kg})$ & $35.6(11.9)$ & $26.3(9.9)$ & $-9.3(-15.1$ to -3.4$)$ & -26 & 0.002 \\
\hline Tw0 (kg) & $8.0(2.4)$ & $6.2(1.7)$ & $-1.8(-3.0$ to -0.6$)$ & -23 & 0.004 \\
\hline OMVC/RF ${ }_{\text {CSA }}\left(\mathrm{g} / \mathrm{mm}^{2}\right)$ & 77.7 (16.8) & $74.5(17.6)$ & $-3.2(-12.4$ to +6.1$)$ & -4 & 0.493 \\
\hline $\operatorname{TwQ} / \mathrm{RF}_{\mathrm{CSA}}\left(\mathrm{g} / \mathrm{mm}^{2}\right)$ & $17.4(3.9)$ & $17.9(3.3)$ & $+0.5(-1.6$ to +2.5$)$ & +3 & 0.657 \\
\hline
\end{tabular}

Data shown as mean (SD). p Values derived from unpaired $t$ tests. Tw0 results reflect supramaximal responses only.

$\mathrm{OMVC}$, quadriceps maximum voluntary contraction; $\mathrm{RF}_{\mathrm{CSA}}$, rectus femoris cross-sectional area; Tw0, quadriceps twitch tension.

$\mathrm{RF}_{\mathrm{CSA}}$ is measured at a marked point). Related ultrasound measurements have studied the response to training; ${ }^{22} 23$ it remains to be investigated whether rectus femoris ultrasound is useful for assessing interventions or longitudinal change in COPD.

A clinician without prior ultrasound experience performed the $\mathrm{RF}_{\mathrm{CSA}}$ measurements following 2 weeks of familiarisation. Scanning was completed more quickly than the quadriceps strength assessment. Visualisation of the rectus femoris border was subjectively easier when less subcutaneous fat was present and $\mathrm{RF}_{\mathrm{CSA}}$ may therefore be unmeasurable in severely obese subjects. Adequate visualisation of intermuscular septa may also be problematic if body fat is grossly depleted. ${ }^{20}$ Measurement of quadriceps muscle thickness ${ }^{24}$ rather than cross-sectional area may be more feasible in such scenarios; however, our personal experience suggests that any excess compression by the ultrasound probe is likely to introduce additional measurement variability. Serial measurements of quadriceps muscle thickness have been studied in an intensive care unit (ICU) population; ${ }^{24}$ however, poor or absent correlations between muscle layer thickness and strength have previously been reported. ${ }^{25}$

Using $\mathrm{RF}_{\mathrm{CSA}}$ as a measure of quadriceps size assumes that all four muscles of the quadriceps group atrophy by a similar amount. Indeed, this pattern has been observed in age-related muscle loss. ${ }^{26}$ The relationship between $\mathrm{RF}_{\mathrm{CSA}}$ and quadriceps cross-sectional area also suggests this may be a reasonable assumption, but the rectus femoris only constitutes approximately $10 \%$ of the total

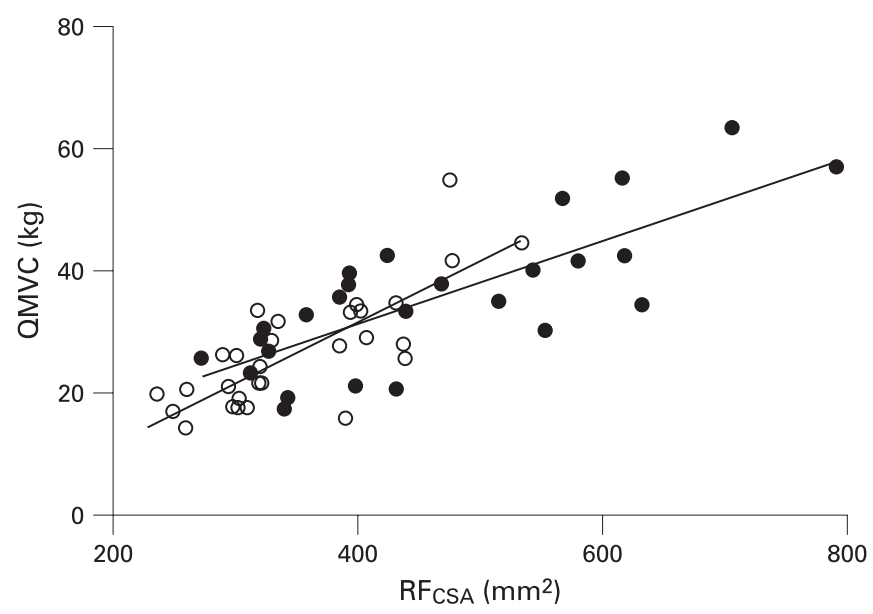

Figure 3 Relationship between rectus femoris cross-sectional area $\left(\mathrm{RF}_{\mathrm{CSA}}\right)$ and quadriceps maximum voluntary contraction (QMVC) in healthy subjects (solid circles) and subjects with chronic obstructive pulmonary disease (open circles). Regression lines for each group are superimposed. Combined regression equation for both groups given by: OMVC (in $\mathrm{kg})=0.077 \times \mathrm{RF}_{\mathrm{CSA}}\left(\right.$ in $\left.\mathrm{mm}^{2}\right)-0.28$. quadriceps cross-sectional area. ${ }^{26}$ Muscle size as measured by $\mathrm{RF}_{\mathrm{CSA}}$ correlated well but not perfectly with maximum voluntary contraction strength in COPD $(r=0.80$ with QMVC). A comparable coefficient (0.73) originally described the relationship between strength and total mid-thigh cross-sectional area measured by CT. ${ }^{12}$ In the 18 subjects who underwent CT scanning, correlations were only slightly improved with crosssectional measures that included the whole quadriceps muscle (see table S2 in online supplement). Additional variation in the relationship between strength and muscle size may arise from differences in muscle quality which were not specifically sought in this study. Reduced tension generation associated with increased muscle lipid content ${ }^{27}$ or altered muscle fibre pennation angles ${ }^{23}$ have been reported in other conditions.

Although OMVC and TwO shared a similar relationship with $\mathrm{RF}_{\mathrm{CSA}}$ in both healthy subjects and patients with COPD, the level of central activation measured by twitch interpolation influenced OMVC force produced per unit of muscle size, as did peripheral oxygen saturation in the patients with COPD. Given that peripheral oxygen saturation had no relationship with TwO per $\mathrm{RF}_{\mathrm{CSA}}$ or absolute MVC, this suggests that volitional measures requiring a degree of physical exertion are subject to additional factors in COPD.

\section{Significance of findings}

In two previous studies the prevalence of quadriceps weakness in COPD has been found to exceed that of whole body FFM depletion. ${ }^{828}$ In the present study FFM was more closely correlated with $\mathrm{RF}_{\mathrm{CSA}}$ in healthy subjects than in those with COPD. However, the interpretation of the disparity between FFM and $\mathrm{RF}_{\mathrm{CSA}}$ depletion warrants caution. FFM calculation in COPD is dependent on electrical bioimpedance and body water content. Group differences in hydration status (or diuretic usage, taken in five patients with COPD and two healthy subjects for uncomplicated essential hypertension) cannot be ruled out. Nevertheless, excess lower limb muscle loss or preferential quadriceps wasting within the leg could also underlie this disparity. For example, the quadriceps may be more sensitive to mechanical unloading associated with inactivity while other leg muscles are relatively preserved; other leg muscle groups were not studied in order to qualify this hypothesis. An increased MRC dyspnoea score (assigned according to breathlessness at different levels of general activity) was related to a reduced $\mathrm{RF}_{\mathrm{CSA}}$ in COPD, independent of FFM or sex. As well as providing prognostic information, the MRC score relates to more detailed quality of life measures ${ }^{29}{ }^{30}$ and the observed relationship may be in keeping with a model of quadriceps weakness driven by inactivity.

A pilot study of serial $\mathrm{RF}_{\mathrm{CSA}}$ measurement in ICU patients is summarised in table S1 in the online supplement. An 18\% reduction in the baseline $R F_{C S A}$ was observed in an unselected 
Table 3 Determinants of $\mathrm{RF}_{\mathrm{CSA}}$

\begin{tabular}{|c|c|c|c|c|c|}
\hline & Model & Covariables & Regression coefficients $(95 \% \mathrm{CI}$ ) & p Value & Model $r^{2}$ \\
\hline \multirow{2}{*}{$\begin{array}{l}\text { Healthy } \\
(\mathrm{n}=26)\end{array}$} & \multirow[t]{2}{*}{ I } & (1) FFM & $6.0(0.9$ to 11.1$)$ & 0.024 & \multirow[t]{2}{*}{0.59} \\
\hline & & (2) $\operatorname{Sex}(F-M)$ & $-120.2(-214.1$ to -26.3$)$ & 0.014 & \\
\hline \multirow{6}{*}{$\begin{array}{l}\text { COPD } \\
(\mathrm{n}=30)\end{array}$} & \multirow[t]{2}{*}{ ॥ } & (1) FFM & $2.4(-1.7$ to 6.5$)$ & 0.240 & \multirow[t]{2}{*}{0.30} \\
\hline & & (2) $\operatorname{Sex}(F-M)$ & $-62.1(-120.8$ to -3.3$)$ & 0.039 & \\
\hline & III & (1) MRCDS & $-76.2(-106.3$ to -46.1$)$ & $<0.001$ & 0.49 \\
\hline & \multirow[t]{3}{*}{ IV } & (1) FFM & $0.6(-2.8$ to 4.1$)$ & 0.708 & \multirow[t]{3}{*}{0.55} \\
\hline & & (2) $\operatorname{Sex}(F-M)$ & $-36.9(-87.1$ to 31.2$)$ & 0.142 & \\
\hline & & (3) MRCDS & $-62.2(-96.1$ to -28.3$)$ & 0.001 & \\
\hline
\end{tabular}

\footnotetext{
FFM, fat-free mass (in $\mathrm{kg}$ ); $\mathrm{RF}_{\mathrm{CSA}}$, rectus femoris cross-sectional area (in $\mathrm{mm}^{2}$ ); MRCDS, Medical Research Council dyspnoea score.

Results of regression analyses performed to investigate the relationship of $F F M$ and sex with $\mathrm{RF}_{\mathrm{CSA}}$ in $\mathrm{mm}^{2}$. All regression models included a constant value. Regression coefficients describe the change in the $\mathrm{RF}_{\mathrm{CSA}}$ (as the dependent variable) per unit change of each covariable.
}

sample of six subjects over 10 days. Comparable reductions in quadriceps strength have been reported in healthy bedbound individuals after 10 days. ${ }^{31}$ Future studies may find ultrasound measurement of the rectus femoris a useful tool for monitoring change which, given the findings described here, may also permit inferences about muscle strength. We caution that a much larger study would be necessary to validate this contention, ideally with parallel measurement of body water and other radiological and muscle contractility assessments.

Improved exercise capacity in advanced COPD can be achieved without a change in lung function, such as following pulmonary rehabilitation. There is likely to be an increased focus on the selection and assessment of patients referred for rehabilitation, including the identification of those with wasted or weak quadriceps muscles. ${ }^{32}$ Certain patients may benefit from advanced techniques such as adjunctive non-invasive ventilation or neuromuscular electrical stimulation. Novel pharmacological interventions may eventually become available which could augment or extend the benefit of rehabilitation on skeletal muscle performance. ${ }^{33}$ Thus, near patient quadriceps assessment may prove increasingly useful in COPD; rectus femoris ultrasound has the advantage of being relatively straightforward to learn, effort-independent and free of ionising radiation.

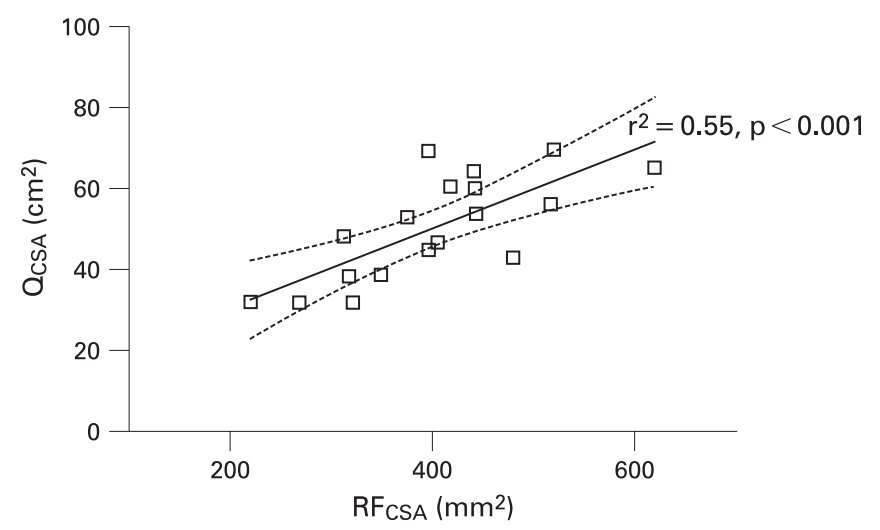

Figure 4 Relationship between rectus femoris cross-sectional area $\left(\mathrm{RF}_{\mathrm{CSA}}\right)$ and total quadriceps cross-sectional area $\left(\mathrm{Q}_{\mathrm{CSA}}\right)$ measured by CT scanning. Squares indicate individual results for $\mathrm{RF}_{\mathrm{CSA}}$ compared with the whole $\mathrm{O}_{\mathrm{CSA}}$ measured by CT scanning. Regression line (solid) and $95 \%$ confidence interval (dashed) shown. Eighteen subjects (10 with COPD, 8 healthy) underwent CT validation of the ultrasound measurements made in this study.
In summary, ultrasound can obtain a measure of quadriceps size at the bedside that is related to maximum isometric strength. Similar to others, we observed a weaker association between quadriceps muscle bulk and FFM in patients with COPD, suggesting that direct lower limb muscle assessmentwhether by ultrasound, CT or strength measurement-is important. Muscle force produced per unit of muscle size during volitional quadriceps strength assessment is dependent on factors extrinsic to the muscle and highlights the importance of patient motivation and cooperation when making such measurements. Ultrasound may prove useful when assessing the quadriceps in COPD or other conditions if non-volitional strength assessment or other scanning modalities are unavailable or impractical.

Funding: JMS was funded by a grant from the British Lung Foundation (P04/8), and was the recipient of an educational grant from GlaxoSmithKline administered by the Royal Brompton Hospital, London. KW was funded by the Stroke Association and the Medical Research Council (UK). JSS was funded by a European Respiratory Society Research Fellowship. CJJ was funded by the Medical Research Council (UK).

Competing interests: None.

Ethics approval: King's College Hospital local research ethics committee approved the study and informed consent was obtained.

\section{REFERENCES}

1. Man WD, Soliman MG, Nikoletou D, et al. Non-volitional assessment of skeletal muscle strength in patients with chronic obstructive pulmonary disease. Thorax 2003;58:665-9.

2. Decramer $\mathbf{M}$, Gosselink R, Troosters $T$, et al. Muscle weakness is related to utilization of health care resources in COPD patients. Eur Respir J 1997;10:417-23.

3. Swallow EB, Reyes D, Hopkinson NS, et al. Quadriceps strength predicts mortality in patients with moderate to severe chronic obstructive pulmonary disease. Thorax 2007:62:115-20.

4. Marquis K, Debigare R, Lacasse $Y$, et al. Midthigh muscle cross-sectional area is a better predictor of mortality than body mass index in patients with chronic obstructive pulmonary disease. Am J Respir Crit Care Med 2002;166:809-13.

5. Edwards RH, Young A, Hosking GP, et al. Human skeletal muscle function: description of tests and normal values. Clin Sci Mol Med 1977;52:283-90.

6. Norregaard J, Lykkegaard JJ, Bulow PM, et al. The twitch interpolation technique for the estimation of true quadriceps muscle strength. Clin Physiol 1997;17:523-32.

7. Polkey MI, Kyroussis D, Hamnegard CH, et al. Quadriceps strength and fatigue assessed by magnetic stimulation of the femoral nerve in man. Muscle Nerve 1996;19:549-55.

8. Engelen MP, Schols AM, Does JD, et al. Skeletal muscle weakness is associated with wasting of extremity fat-free mass but not with airflow obstruction in patients with chronic obstructive pulmonary disease. Am J Clin Nutr 2000;71:733-8.

9. Steiner MC, Barton RL, Singh SJ, et al. Bedside methods versus dual energy X-ray absorptiometry for body composition measurement in COPD. Eur Respir $J$ 2002;19:626-31.

10. Sipila S, Suominen H. Muscle ultrasonography and computed tomography in elderly trained and untrained women. Muscle Nerve 1993:16:294-300. 
11. Reeves ND, Maganaris CN, Narici MV. Ultrasonographic assessment of human skeletal muscle size. Eur J Appl Physiol 2004;91:116-8.

12. Bernard S, LeBlanc P, Whittom F, et al. Peripheral muscle weakness in patients with chronic obstructive pulmonary disease. Am J Respir Crit Care Med 1998:158:629-34.

13. Mathur S, Takai KP, Macintyre DL, et al. Estimation of thigh muscle mass with magnetic resonance imaging in older adults and people with chronic obstructive pulmonary disease. Phys Ther 2008;88:219-30.

14. Pauwels RA, Buist AS, Calverley PM, et al. Global strategy for the diagnosis, management, and prevention of chronic obstructive pulmonary disease. NHLBI/WHO Global Initiative for Chronic Obstructive Lung Disease (GOLD) Workshop summary. Am J Respir Crit Care Med 2001;163:1256-76.

15. Fletcher CM, Elmes PC, Fairbairn AS, et al. The significance of respiratory symptoms and the diagnosis of chronic bronchitis in a working population. BMJ 1959;2:257-66.

16. Miller MR, Hankinson J, Brusasco V, et al. Standardisation of spirometry. Eur Respir J 2005:26:319-38.

17. de Bruin PF, Ueki J, Watson A, et al. Size and strength of the respiratory and quadriceps muscles in patients with chronic asthma. Eur Respir J 1997;10:59-64.

18. Bland JM, Altman DG. Statistical methods for assessing agreement between two methods of clinical measurement. Lancet 1986;1:307-10.

19. Sidhu PS, Desai SR. A simple and reproducible method for assessing intimal-medial thickness of the common carotid artery. Br J Radiol 1997:85-9.

20. Hudash G, Albright JP, McAuley E, et al. Cross-sectional thigh components: computerized tomographic assessment. Med Sci Sports Exerc 1985;17:417-21.

21. Mitsiopoulos N, Baumgartner RN, Heymsfield SB, et al. Cadaver validation of skeletal muscle measurement by magnetic resonance imaging and computerized tomography. J Appl Physiol 1998;85:115-22.

22. Sipila S, Suominen H. Quantitative ultrasonography of muscle: detection of adaptations to training in elderly women. Arch Phys Med Rehabil 1996;77:1173-8.
23. Aagaard P, Andersen JL, Dyhre-Poulsen P, et al. A mechanism for increased contractile strength of human pennate muscle in response to strength training changes in muscle architecture. J Physiol 2001;534:613-23.

24. Gruther W, Benesch T, Zorn C, et al. Muscle wasting in intensive care patients: ultrasound observation of the M. quadriceps femoris muscle layer. J Rehabil Med 2008:40:185-9

25. Sipila S, Suominen H. Ultrasound imaging of the quadriceps muscle in elderly athletes and untrained men. Muscle Nerve 1991;14:527-33.

26. Trappe TA, Lindquist DM, Carrithers JA. Muscle-specific atrophy of the quadriceps femoris with aging. J Appl Physiol 2001;90:2070-4.

27. Goodpaster BH, Carlson CL, Visser M, et al. Attenuation of skeletal muscle and strength in the elderly: the Health ABC Study. J Appl Physiol 2001;90:2157-65.

28. Hopkinson NS, Tennant RC, Dayer MJ, et al. A prospective study of decline in fat free mass and skeletal muscle strength in chronic obstructive pulmonary disease. Respir Res 2007:8:25.

29. Bestall JC, Paul EA, Garrod R, et al. Usefulness of the Medical Research Council (MRC) dyspnoea scale as a measure of disability in patients with chronic obstructive pulmonary disease. Thorax 1999;54:581-6.

30. Celli BR, Cote CG, Marin JM, et al. The body-mass index, aifflow obstruction, dyspnea, and exercise capacity index in chronic obstructive pulmonary disease. N Engl J Med 2004;350:1005-12.

31. Kortebein P, Ferrando A, Lombeida J, et al. Effect of 10 days of bed rest on skeletal muscle in healthy older adults. JAMA 2007;297:1772-4.

32. Spruit MA, Vanderhoven-Augustina I, Janssen PP, et al. Integration of pulmonary rehabilitation in COPD. Lancet 2008;371:12-3.

33. Narkar VA, Downes M, Yu RT, et al. AMPK and PPARdelta agonists are exercise mimetics. Cell 2008;134:405-15.

\section{Lung alert}

\section{Detection of pulmonary scarring by chest radiography and lung cancer risk}

The relationship between lung scarring and lung cancer is uncertain, although it has been postulated that inflammation induces genetic damage leading to DNA mutations with a resultant increase in the risk of scar cancers.

In this study, using analysis of data from the prostate, lung, colorectal and ovarian cancer screening trial, the authors tried to establish a relationship between scarring and lung cancers. Of 66863 cancer-free participants aged 55-74 years who completed baseline questionnaires and had PA chest radiographic examinations and follow-up for 12 years, 5041 (7.5\%) had baseline scarring radiographically; 809 (16\%) of these had an elevated risk for lung cancer after adjustments for age, gender, race and cigarette smoking. The relationship between scarring and lung cancer was specific for cancers ipsilateral to the scarring. The risk of developing ipsilateral lung cancer was twofold higher and remained so throughout the 12 years of the study. Lung cancer risk was especially high in individuals with diffuse scarring. The commonest cancer detected was adenocarcinoma.

Scars were more commonly reported in the base of the left lung. The authors postulated that this was due to cardiac shadowing and atelectesis more commonly occurring here. Pleural plaques were also sometimes misdiagnosed as lung scarring. Although this study relied on radiographic diagnoses of lung scarring, the authors concluded that old scars do increase the risk of lung cancer. Perhaps there is a role for clinical monitoring for lung cancer.

- Yu YY, Pinsky PF, Caporaso NE, et al. Lung cancer risk following detection of pulmonary scarring by chest radiography in the prostate, lung, colorectal and ovarian cancer screening trial. Arch Intern Med 2008;168:2326-32.

\section{S Adejumo}

Correspondence to: Dr S Adejumo, Department of Respiratory Medicine, Royal Albert Edward Infirnary, Wigan WN1 2NN, UK; steve.adejumo@wwl.nhs.uk 